\title{
Transesophageal Evaluation of Reconstructive Surgery for Aortic Valve Stenosis
}

\author{
Tanja Anguseva ${ }^{1 *}$, Zan Mitrev$^{1}$, Milka Zdravkovska ${ }^{2}$ \\ ${ }^{1}$ Zan Mitrev Clinic, Skopje, Republic of Macedonia; ${ }^{2}$ Faculty of Medical Science, University Goce Delchev, Stip, Republic of \\ Macedonia
}

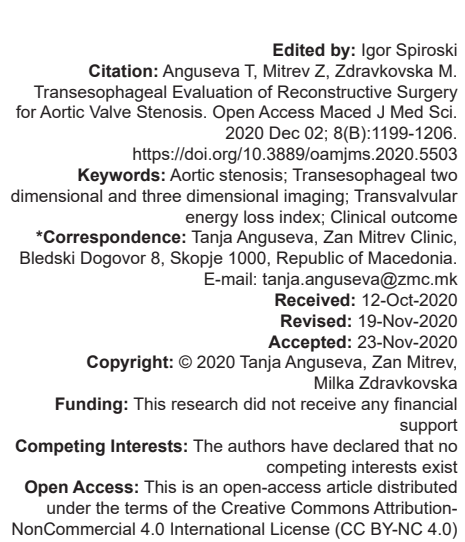

\section{Introduction}

Aortic stenosis (AS) is the most prevalent valvular disease in developed countries. The incidence rate has a variation from $4 \%$ to $7 \%$ in patients $>65$ years of age [1], [2]. Among those patients who are diagnosed with AS, the optimal timing of surgery needed to be clarified based predominantly on the presence of severe stenosis on imaging and clinical symptoms attributable to valvular disease. Echocardiography plays a major role in the diagnosis and management of AS.

Two-dimensional (2D) transthoracic echocardiography (TTE) is the standard method of severity evaluation. Severe AS is historically defined as aortic jet velocity $>4.0 \mathrm{~m} / \mathrm{s}$, mean Doppler gradient (MG) $>40 \mathrm{mmHg}$, or aortic valve area (AVA) $<1.0 \mathrm{~cm}^{2}$ [2] (Table 1). These cutoffs are based on previous studies of AS without surgical intervention [4], [5], [6].
The last criteria for AS graduation of the European and American Society for echocardiography are presented in the next table (Table 1).

Transesophageal 2D and three-dimensional (3D) evaluations give superior data for aortic valve morphology, as well as dimensions, and help clinicians decide if it is a better option to treat the patient conservatively or with a surgical replacement.

$3 D$ versus $2 \mathrm{D}$ echocardiographic imaging techniques provide more accurate and adequate 3D images of the valve. Clinician can get space orientation of the position of the aortic valve in correlation with mitral valve, better image of left ventricle outflow tract (LVOT), and its dimensions, as well as ascending aorta and tricuspid valve. 3D dimensions of the AVA and evaluation of the condition of the left chamber are more accurate. All these parameters are of vital importance when making a decision for further patient's treatment [9]. 
Table 1: Graduation of severity of AS depending of measured pressures, velocity, AVA, and AVA index -indexed AVA /BSA (body surface area)

\begin{tabular}{lllll}
\hline Echo parameters & Aortic sclerosis & Mild & Medium & Severe \\
\hline Ao velocity & $<2.5 \mathrm{~m} / \mathrm{s}$ & $2.6-2.9 \mathrm{~m} / \mathrm{s}$ & $3.0-4.0 \mathrm{~m} / \mathrm{s}$ & $>4 \mathrm{~m} / \mathrm{s}$ \\
Mean pressure gradient & & $<20(<30)$ & $20-40(30-50)$ & $>40$ \\
$(\mathrm{mmHg})$ & & & & \\
AVA cm & & $>1.5$ & $1-1.5$ & $<1$ \\
AVA index $\left(\mathrm{cm}^{2} / \mathrm{m}^{2}\right)$ & & $>0.85$ & $0.6-0.85$ & $<0.6$ \\
Velocity ratio & & $>0.5$ & $0.25-0.5$ & $<0.25$ \\
\hline AS: Aortic stenosis, AVA: Aortic valve an
\end{tabular}

AS: Aortic stenosis, AVA: Aortic valve area.

\section{Subjects and Methods}

\section{Study population}

The study population consisted of 377 patients with findings of severe AS, referred to Zan Mitrev Clinic between the period of 02/2002 and 06/2020. Patients were included following actual guidelines of the European Society of Cardiology for valvular disease, whereas patients with dilatation of aortic annulus, rheumatoid arthritis, and chronic program on hemodialysis were excluded from the study. All of the patients were older than 18 years and had clinical symptoms for severe AS.

\section{Demographics}

Basic demographic data on all subjects were obtained by retrospective review of clinical charts. Patients' available demographics and comorbid conditions included age, gender, and presence of diabetes mellitus, systemic hypertension, hyperlipidemia, coronary artery disease, and chronic kidney disease.

\section{Echocardiography}

Transthoracic (TTE) and transesophageal echocardiography (TEE) were performed using one of several commercially available echocardiography systems (Philips IE 33) with standard views and techniques as recommended by the American and by the European Society of Echocardiography (ASE, ESE). The LVOT was imaged in zoom mode in the parasternal long-axis view using harmonic imaging. The gain was adjusted to optimize the blood tissue interface. As recommended [2], LVOT diameter was measured in mid-systole from the inner edge to inner edge just below the insertion of the aortic valve leaflets (Figure 1a). TEE was performed using one of several commercially available echocardiography systems (Philips IE 33) and a 4-7 MHz probe; the LVOT was imaged in zoom mode in the mid-esophageal long-axis view (typically $\sim 130$ degrees) during mid-systole from the inner edge to inner edge (Figure 1b) [13].

Other available standard B-mode and Doppler measurements were obtained from the existing echocardiography reports. Of note, all Doppler

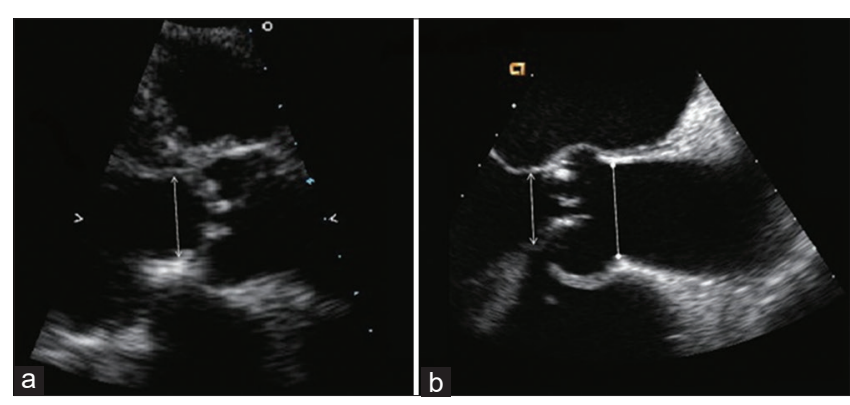

Figure 1: ( $a$ and b) Longitude view of the aortic root. (a) Measurement of the left ventricle outflow tract, (b) marked full aortic root with a measurement of sinotubular junction

parameters for atrial fibrillation were averaged over 5 to 10 cardiac cycles. Left ventricular EF was based on the TTE study. AVA was measured on a perpendicular image of the valve by 2D and 3D TEE.

\section{Physiologic parameters}

Echocardiographic morphological and physiological parameters such is transvalvular energy loss, as an independent predictor for clinical outcome after aortic valvular replacement (AVR), which could help clinicians when making a decision for further treatment. Energy loss index (ELI) can be calculated using the validated equation AVA $\times \mathrm{Aa} /(\mathrm{Aa}-\mathrm{AVA}) / \mathrm{m}^{2}$, where $A a$ is the aortic area at the level of the sinotubular junction and $\mathrm{m}^{2}$ is the body surface area [7], [14].

\section{Description of the surgical technique}

After median sternotomy and standard pericardial scission, we cannulated the aortic arch and the right atrium according to the protocol for aortic valve surgery, and the patient is connected to the extracorporeal circulation in a condition of mild hypothermia. Using a mild blood $(\mathrm{k} / \mathrm{mg})$ cardioplegia, suprannular aortotomy is performed and we extirpate native destructed valve. Using the measurements of AVA, LVOT, aortic annulus, and leaflet dimensions, new created leaflets can be tailored in a semilunar shape, from bovine or equine or matrix pericardium patch. After that, every leaflet is sutured on the aortic annually separately, and at the end, intercommisural junctions have to be created. In the end, we close the aorta and avoid the patient from the extracorporeal machine on a standard way.

\section{Statistical analysis}

All analyses were performed using basic demographic analysis. Continuous variables were reported as mean \pm standard deviation. Student's t-test and two-way analysis of variance (ANOVA) were used for continuous variables. Pearson's Chi-square contingency test was used to compare categorical 
variables. Multiple linear regression analysis was used to model the relationship between $\geq 2$ explanatory variables. $p<0.05$ was considered statistically significant. Data were reported with a $95 \%$ confidence interval estimate, and all reported $p$ values were 2 -sided.

\section{Results}

In our study were included 377 patients, with an average age of $66.3 \pm 9.9$ years. Two hundred eleven $(55.97 \%)$ were males and 166 (44.03\%) females. One hundred fourteen (30.3\%) had severe AS and $263(69.7 \%)$ had combined AS and insufficiency. One hundred $(26.5 \%)$ had small aortic root. Comorbidities and demographic data of all patients with severe AS are shown in Table 2.

Table 2: Comorbidities and demographic characteristics of patients

\begin{tabular}{|c|c|c|c|c|c|}
\hline \multirow[t]{2}{*}{ Comorbidities } & \multicolumn{2}{|l|}{ Mail (\%) } & \multicolumn{2}{|l|}{ Female (\%) } & \multirow{2}{*}{$\begin{array}{l}\text { Mann-Whitney } \\
\text { U test } \\
\text { p-level }\end{array}$} \\
\hline & No & Yes & No & Yes & \\
\hline Diabetes & $161(76.3)$ & $50(23.7)$ & 119 (71.7) & $47(28.3)$ & 0.3093 \\
\hline Hyperlipidemia & $58(27.5)$ & $153(72.5)$ & $46(27.7)$ & $120(72.3)$ & 0.9617 \\
\hline Hypertension & $14(6.6)$ & $197(93.4)$ & $13(7.8)$ & $153(92.2)$ & 0.6551 \\
\hline Smoking & $175(82.9)$ & $36(17.1)$ & $154(92.7)$ & $12(7.2)$ & $0.0045^{\star}$ \\
\hline Obesity & 209 (99.1) & $1(0.9)$ & $151(90.9)$ & $15(9.1)$ & $0.0001^{*}$ \\
\hline COPD & 195 (92.4) & $16(7.6)$ & $158(95.2)$ & $8(4.8)$ & 0.2758 \\
\hline Renal insufficiency & $192(91.0)$ & $19(9.0)$ & $156(94.0)$ & $10(6.0)$ & 0.2816 \\
\hline
\end{tabular}

In Table 2, we present patient distribution according to sex, as well as patient's comorbidities. There were 16 bicuspid aortic valves and two unicuspid valve. When comparing the comorbidities between male and female patients, we realized that there was no difference according to diabetes, hyperlipidemia, and hypertension between both sexes, but in male patients, smoking and COPD were much more present, whereas female patients were more obese. About $88.5 \%$ of the patients were with severe AS of degenerative (calcific) etiology, $5.3 \%$ endocarditis, $3.98 \%$ rheumatic fever, and $2.12 \%$ congenital etiology.

Pre-operative ultrasound measurements were performed by transthoracic ultrasound probe. Mean pressure gradient through the LVOT was measured in a standard left decubitus position through the long axis using a TTE. Velocity measurement of the stenotic valve was done on TTE through apical or right parasternal image. Intraoperatively before the surgery and after surgery, we performed a transesophageal evaluation. Echocardiographic parameters are shown in Table 3.

Mann-Whitney $U$ test analyzes pointed out that female patients with AS had smaller dimensions of the left ventricle, aortic annulus, and more significant hypertrophy of the myocardium with a preserved ejection fraction (EF). According to the performed surgery, we divided estimated patients in four groups (Table 4).

Kruskal-Wallis ANOVA: $\mathrm{H}=1.351 \mathrm{p}=0.7170$ analyzes showed that there were no significant
Table 3: Echocardiographic parameters

\begin{tabular}{lllll}
\hline Echocardiographic parameters & Z & p-level & Valid N & Valid N \\
\hline LVEDD/mm - before operation & 7.26060 & 0.000001 & 211 & 166 \\
LVESD/mm - before operation & 6.46537 & 0.000001 & 211 & 166 \\
LVEDV/ml - before operation & 6.61316 & 0.000001 & 210 & 165 \\
LVESV/ml - before operation & 6.07094 & 0.000001 & 210 & 165 \\
IVSd/mm - before operation & -2.26945 & 0.023241 & 211 & 166 \\
LVPWD/mm - before operation & 0.32300 & 0.746698 & 211 & 166 \\
SV/ml - before operation & 3.97137 & 0.000071 & 209 & 165 \\
EF (\%) - before operation & -3.20249 & 0.001363 & 210 & 166 \\
Al -before operation & 1.72004 & 0.085425 & 210 & 166 \\
Diameter of annulus/cm - before operation & 5.79447 & 0.000001 & 211 & 166 \\
AVA/cm ${ }^{2}$ - before operation & 2.49591 & 0.012564 & 211 & 165 \\
PG max/mmHg - before operation & -3.88693 & 0.000102 & 211 & 164 \\
PG mean/mmHg - before operation & -3.48179 & 0.000498 & 211 & 164 \\
LVEDD/mm - post operation & 7.26060 & 0.000001 & 211 & 166 \\
LVESD/mm - post operation & 6.46537 & 0.000001 & 211 & 166 \\
LVEDV/ml - post operation & 6.60020 & 0.000001 & 210 & 165 \\
LVESV/ml - post operation & 6.05414 & 0.000001 & 210 & 165 \\
SV/ml - post operation & 3.94489 & 0.000080 & 209 & 165 \\
EF (\%) - post operation & -3.23175 & 0.001230 & 210 & 166 \\
Al - post operation & 0.38216 & 0.702346 & 209 & 162 \\
EOA/cm - post operation & 5.18396 & 0.000001 & 211 & 166 \\
Diameter of aortic annulus/cm - post & 7.70445 & 0.000001 & 143 & 115 \\
operation & & & & \\
Transvalvular ELI & -1.16829 & 0.242693 & 210 & 166 \\
PG max/mmHg - post operation & -1.55387 & 0.120216 & 211 & 166 \\
PG mean/mmHg - post operation & -1.65753 & 0.097413 & 211 & 166 \\
\hline Data expressed as n (\%) for categorical variables and mean \pm standard deviation for continuous variables. \\
TEE: Transthoracic echocardiogram, EF: Ejection fraction, SVI: Stroke volume index, MG: Mean Doppler \\
gradient, AVAl: Aortic valve area index, LVOT: Left ventricular outflow tract, AV: Aortic valve, ELI: Energy \\
loss index. Al: Aortic insufficiency, LVEDD: Left ventricular external end-diastolic diameter, LVESD: Left \\
ventricular end-systolic dimension, LVEDV: Left ventricular end-diastolic volume, LVESV: Left ventricular \\
end-systolic volume, Al: Aortic insufficiency. & & & & \\
& & & &
\end{tabular}

differences between the group according to measured dimensions of AVA preoperatively.

The result of Kruskal-Wallis ANOVA: $\mathrm{H}=1.351$ $p=0.7170$ of the pre-operative echocardiographic measurement showed no differences between the groups according to the dimensions of AVA or measured EOA of the new created valve postoperatively (Figures 2 and 3 ).

Table 4: Patients distribution according to performed surgery and NYHA classification

\begin{tabular}{|c|c|c|c|c|}
\hline \multirow{2}{*}{ Group } & \multicolumn{3}{|c|}{ The NYHA } & \multirow[t]{2}{*}{ Total } \\
\hline & Staging II & Staging III & Staging IV & \\
\hline $\begin{array}{l}\text { Reconstructive surgery with replacement of } \\
\text { three leaflets (N1) }\end{array}$ & $\begin{array}{l}24 \\
13.33 \%\end{array}$ & $\begin{array}{l}145 \\
80.56 \%\end{array}$ & $\begin{array}{l}11 \\
6.11 \%\end{array}$ & 180 \\
\hline $\begin{array}{l}\text { Combined surgery - Reconstructive surgery } \\
\text { with replacement of three leaflets and CABG } \\
\text { (N2) }\end{array}$ & $\begin{array}{l}7 \\
5.79 \%\end{array}$ & $\begin{array}{l}104 \\
85.95 \%\end{array}$ & $\begin{array}{l}10 \\
8.26 \%\end{array}$ & 121 \\
\hline $\begin{array}{l}\text { Combined surgery - Reconstructive surgery } \\
\text { with replacement of three leaflets and mitral } \\
\text { or tricuspid valv.surg (N3) }\end{array}$ & $\begin{array}{l}1 \\
3.03 \%\end{array}$ & $\begin{array}{l}25 \\
75.76 \%\end{array}$ & $\begin{array}{l}7 \\
21.21 \%\end{array}$ & 33 \\
\hline $\begin{array}{l}\text { Combined surgery - Reconstructive surgery } \\
\text { with replacement of three leaflets and CABG } \\
\text { mitr. And tric surg and aortoplasty (N4) }\end{array}$ & $\begin{array}{l}3 \\
6.98 \%\end{array}$ & $\begin{array}{l}30 \\
69.77 \%\end{array}$ & $\begin{array}{l}10 \\
23.26 \%\end{array}$ & 43 \\
\hline All groups & 35 & 304 & 38 & 377 \\
\hline
\end{tabular}

Mean measured values of EF\% were the lowest in the third group with a performed reconstructive surgery of the stenotic aortic valve in combination with surgery of the mitral and tricuspid one but without any statistical significance.

Kruskal-Wallis ANOVA: $\mathrm{H}=18.054 \mathrm{p}=0.0004$

Postoperatively, we measured mean and maximal pressure gradient through the new created valve, effective orifice area, and diameter of aortic annulus.

With a Mann-Whitney $U$ test, we calculated that there was significant sex dependent differences. In male patients, we measured bigger dimensions for 


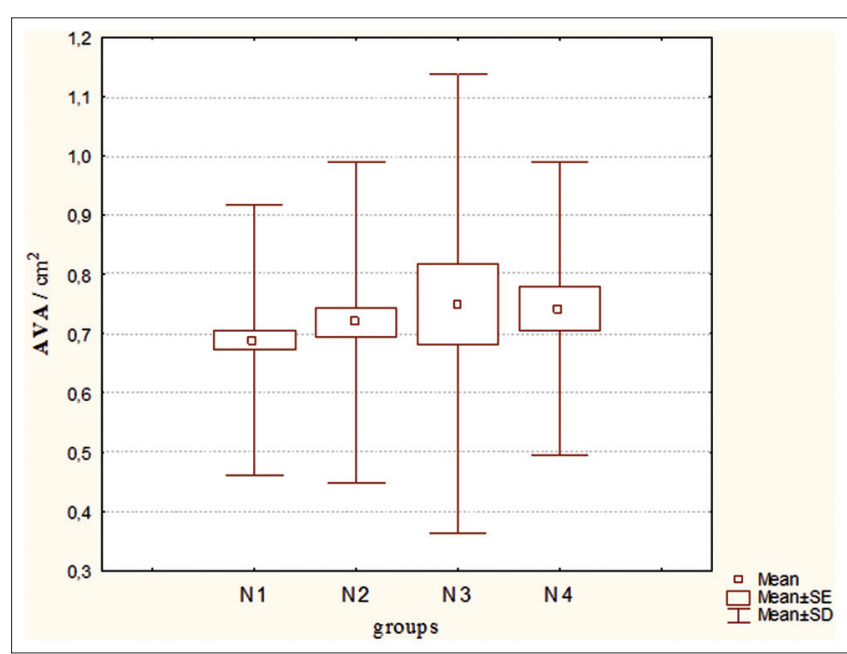

Figure 2: Mean values of AVA in different groups

effective orifice area (post-operative measured opening orifice of new created valve) (Table 3 ).

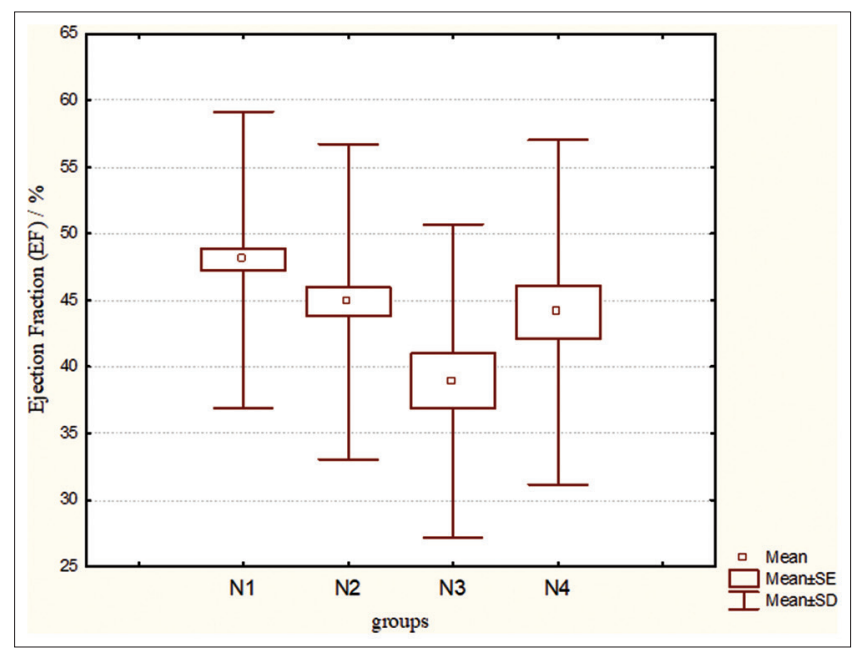

Figure 3: Mean values of EF (\%) in different groups

By performing a Kruskal-Wallis ANOVA $(H=5.654 p=0.1297)$, we realized that there was no significant difference in mortality rate between the different surgical groups, and there was also no statistically significant difference in correlation with ELI (Figure 4).

We found a strong correlation between ELI and pre-operative measured AVA dimensions $(r=-96)$, whereas there was a weak correlation with the EF $(r=0.08)$ and no correlation with the measured pressure gradients in LVOT (PGmax and PGmean).

The morphology of the new created valve was analyzed on perpendicular view (TEE 45-60 ${ }^{\circ}$ ), as well as longitudinal axis $\left(120-130^{\circ}\right)$ with $2 \mathrm{D}$ and $3 \mathrm{D}$ TEE technique.

With transesophageal 2D and 3DTEE technique, we evaluated the performances of the stenotic and newly created aortic valve. The morphology of the valve was close to the native one, as shown in Figures 5-8. The hemodynamic performances PGmean and PGmax were close to the native normal aortic valve (Table 3 ).

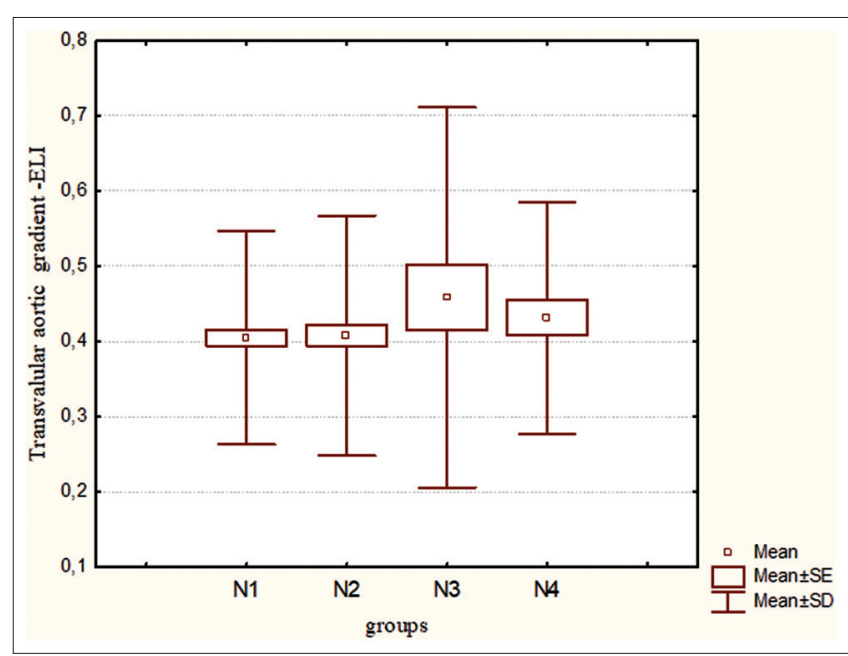

Figure 4: Mean values of transvalvular energy loss index in different groups

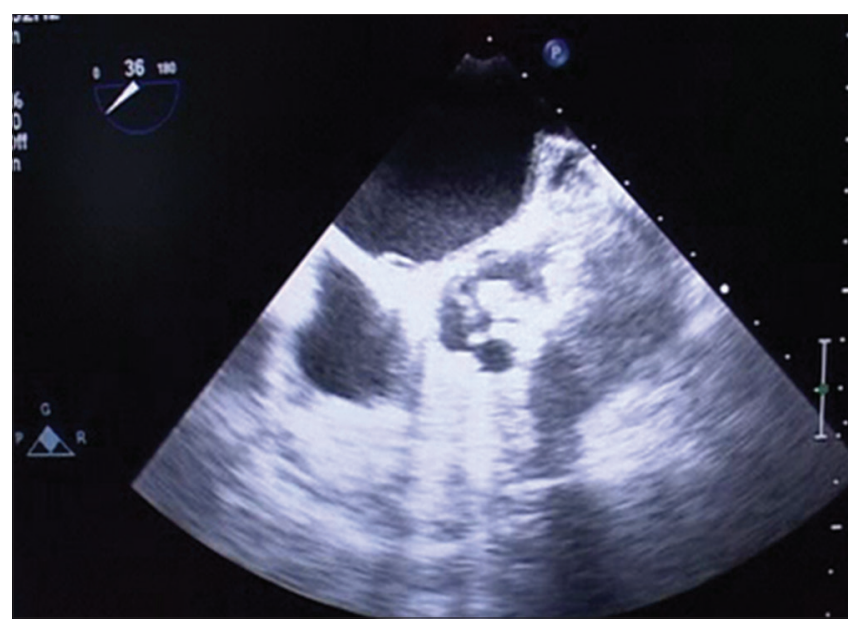

Figure 5: Pre-operative transesophageal image of the stenotic aortic valve-perpendicular view

When analyzing the post-operative clinical outcome, per se, mortality rate, we realized that there was a strong correlation between mortality rate and ELI (Table 5).

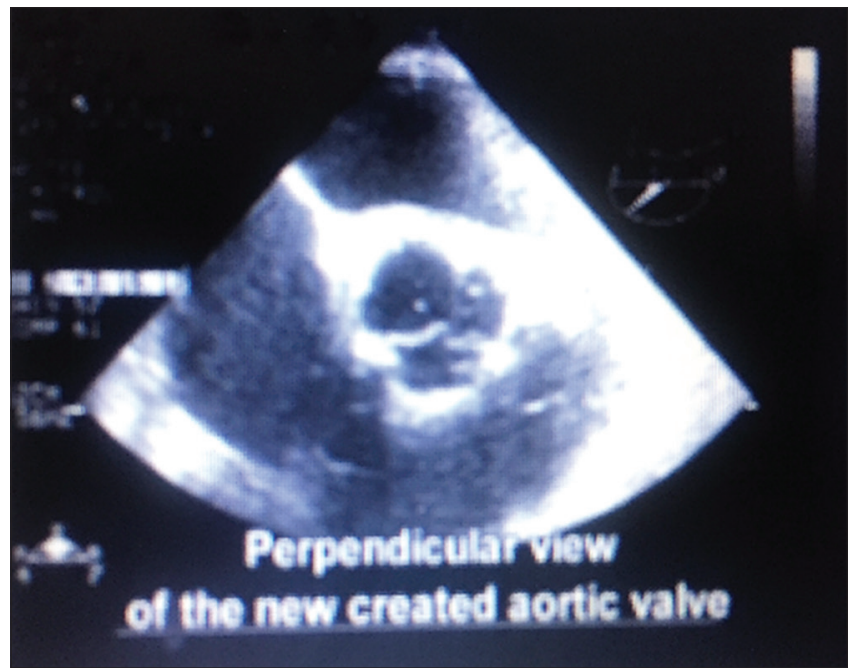

Figure 6: Post-operative two-dimensional image of the new created valve 


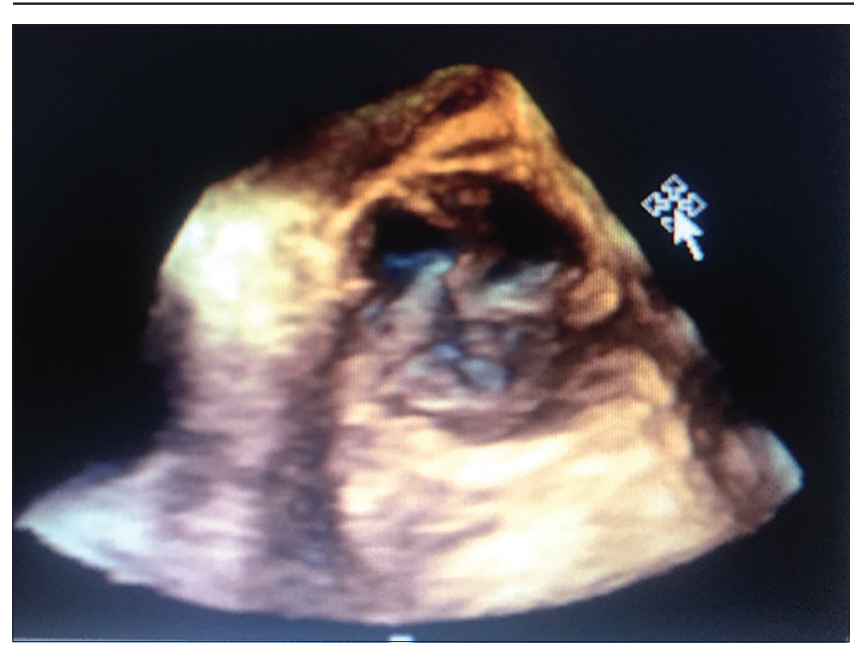

Figure 7: Post-operative three dimensional image of the new created valve

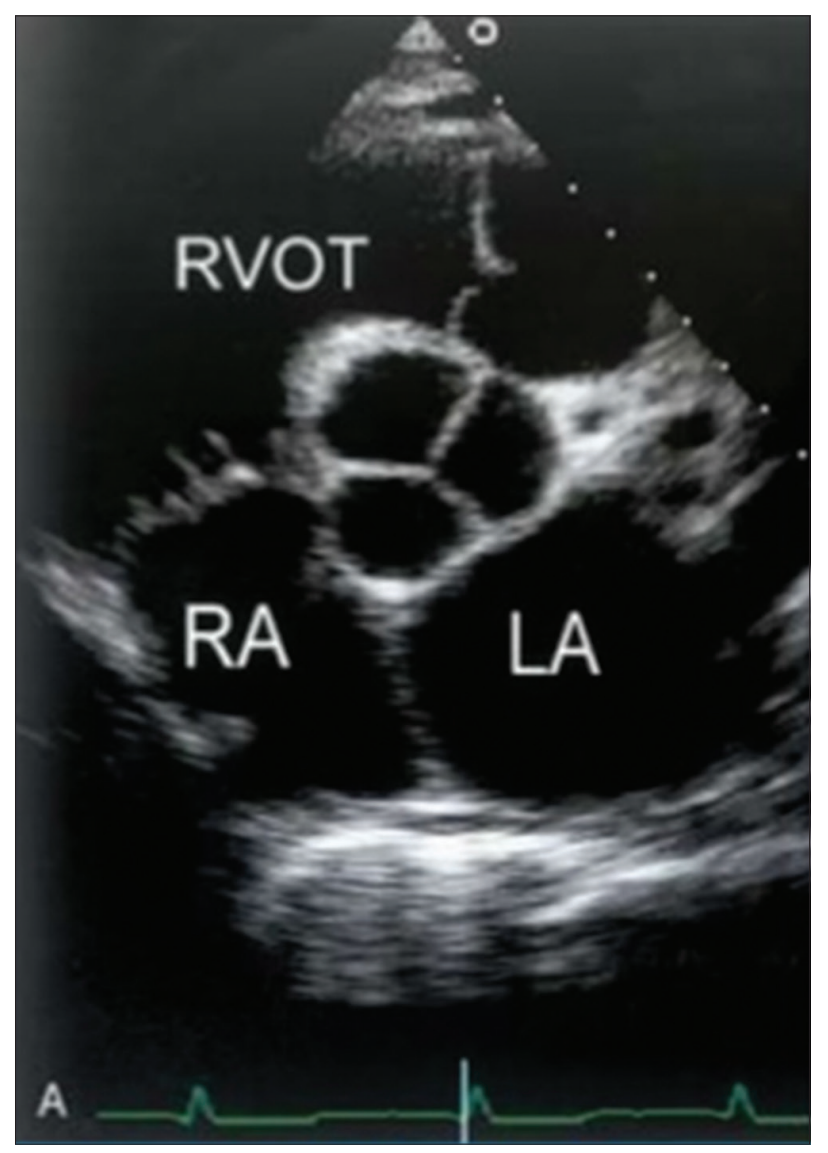

Figure 8: Normal aortic valve

Pearson Chi-squared test $\chi^{2}=4.911$ $\mathrm{df}=1 \mathrm{tp}=0.02669)$ analyzes pointed that patients with calculated ELI $<0.42 \mathrm{~cm}^{2} / \mathrm{m}^{2}$ have a higher mortality rate $(8.7 \%)$ in correlation with those one who are with ELI $>0.42 \mathrm{~cm}^{2} / \mathrm{m}^{2}$.

Table 5: Mortality rate in correlation with ELI

\begin{tabular}{llll}
\hline Transvalvular aortic gradient (ELI) & \multicolumn{2}{l}{ Mortality } & Total \\
\cline { 2 - 3 } & Exitus letalis & Alive & \\
\hline ELI 0.42 & 33 & 175 & 208 \\
ELI> 0.42 & $8.7 \%$ & $92.3 \%$ & $100 \%$ \\
& 14 & 155 & 169 \\
All groups & $3.7 \%$ & $96.3 \%$ & $100 \%$ \\
\hline ELI: Energy loss index. & 47 & 330 & 377 \\
\hline
\end{tabular}

An ELI of $<0.42 \mathrm{~cm}^{2} / \mathrm{m}^{2}$ is proposed as a cutoff for severe AS [7], and as such, reportedly predicts poor outcomes in patients with severe AS [8]. In the present study, the mean ELI for patients with severe AS was smaller in the group of patients with measured smaller AVA, whereas pressure gradients do not have an influence, and a weak correlation was found with EF. Moreover, Garcia et al. got the same conclusions from their trial [7].

\section{Discussion}

The main findings of this study can be summarized as follows:

1. TEE $-2 D$ and $3 D$ imaging of the stenotic aortic valve is an important tool which gives important parameters for surgeons on the operative field about severity of the disease and much more that controls the results from the performed surgery

2. The severity of the AS and the clinical outcome does not depend only from the morphological parameters such as measured AVA, the diameter of the aortic annulus, or the measured pressured gradients, and the influence of the whole hemodynamic expressed through the ELI is very important

3. Thus, TEE may be considered before high-risk intervention for severe AS. Despite preserved, EF positive clinical outcome did not always come, and consequently, that is why the physiological parameter ELI was included in this trial [16], [17], [20].

The evaluation of the AS depends from patients technical and physiological parameters. The technical parameters are associated with technical parameters of the ultrasound probe as well as patients general characteristics such are BMI, blood pressure, and heart frequency. Measured pressure gradients are proportionally dependent with systemic patient pressure, whereas increased heart frequency and stroke volume together form a grade separation [18].

There are several physiological parameters such as:

1. The pressure gradient through the LVOT in a longer period results with subendocardial ischemia and fibrosis, which decrease the spiral movements of contraction and elongation of the mitral ring during cardiac cycle. Stroke volume and pressure gradient through the LVOT decrease without any influence on the EF

2. The concentric hypertrophy of the left chamber forces the diastolic left chamber dysfunction and impairment filling of the chamber

3. Transvalvular energy loss, like a parameter, demonstrates the preserved myocardial power 
in patients with AS. ELI depends from exchange of static and dynamic power during one heart's cycle, which means that when the aortic valve is stenotic changed, the myocardium spends more energy to push the blood through the valve in the ascending aorta. In a longer period, this can result with a decreased ELI (calculated by ELI equitation). The patient can have a normal EF, but due to morphological changes such as aortic stenos and dilatation of ascending aorta diameter ELI can decrease, so in the post-operative period, we realized that a longer in-hospital stay results with a worse final clinical outcome [19].

4. The mitral valve stenosis or insufficiency, right chamber failure, and constrictive pericarditis are burdensome factors that force the left chamber falling [23], [26].

Although multimodality imaging such as CT scan or magnetic resonance has improved our understanding of LVOT geometry, in any case, the golden standard for diagnosis of AS is echocardiography [3]. Transesophageal ultrasound evaluation ensures much more parameters for the assessment of patomorphology of the AS. Especially 3D imaging technique ensures visualization of the spatial correlation of the aortic valve with mitral and tricuspid one, as well as morphological analyzes of the LVOT tract, systolic anterior movement of the anterior mitral leaflet, and the severity as well geometrics of the left ventricle hypertrophy. Despite the fundamental assumption that the LVOT is circular, differing aortic valve leaflet geometry can lead to variable measurements [11]. Specifically, the ellipticity of the LVOT reportedly results in an underestimation of AVA by echocardiography [11]. Moreover, poor echocardiographic image quality and heavy calcification with secondary acoustic blooming can decrease the accuracy of measurements, which is why 3D TEE images have an advantage when it comes to evaluating these groups of patients [10], [24].

TEE measurements are considered closest to a gold standard on the basis of superior spatial resolution and better correlation of TEE when compared to MSCT and magnetic resonance imaging in prior studies [21], [22]. This does not fully eliminate the risk of misalignment and underestimation of the true crosssectional area of LVOT. 3D echocardiography was crucial and superior to conventional (2D) techniques for AVA measurement [15], [23].

Immediately postoperatively, 2D and 3D TEE analyzes of estimated patients with reconstructive surgery for aortic valve stenosis showed that new created valve with a separate sutured leaflet on the aortic ring according to the morphology was much closer to the native one. Systolic separation of the leaflets and diastolic closure does not differ from the native normal valve. Basic hemodynamic parameters such are mean and maximal pressure gradients measured in the LVOT tract were in normal values.
Physiologic parameter like ELI was very useful when analyzing post-operative adversative outcomes such as mortality rate. The correlation between ELI and the mortality rate pointed out that patients with severe AS and post-stenotic dilatation of the ascending aorta were with worse prognosis $(E L \mid<0.42)$. Patients with the same values of measured AVA got different values for ELI depending on the measured diameter of the sinotubular junction of the ascending aorta. Patients with a bigger sinotubular junction had smaller ELI and bigger mortality rate. ELI, like a physiologic parameter, helped us to recognize the level of myocardial reserve for recovery after performed surgery. We realized that the mortality rate even in patients with a small root aorta is not correlated with the dimensions of LVOT, but there is a strong correlation with the calculated ELI [14], [25].

\section{Limitations}

This was a single centered study and the study population underwent both TTE and TEE within a short period, pre-operation, and early post-operative. The weakness of the study is that we did not include nonechocardiographic measurements, that is, MSCT or magnetic resonance, which might help us strengthen the conclusion.

\section{Conclusions}

Real stentless aortic valve bioprosthesis is with similar morphology and hemodynamic parameters as a normal native valve. The assessment of AV morphology, anatomy of the functional aortic annulus (FAA), and the aortic root with TEE improves the understanding of the mechanisms of AR. Pre- and intra-operative TEE plays a pivotal role in guiding case selection, surgical planning, and evaluating procedural success. Post-operative transthoracic echocardiography is useful to determine long-term success and monitor for recurrence of AR.

\section{Acknowledgments}

We would like to thank ZMC staff for dedication and passion in the treatment of patients.

\section{References}

1. Nkomo VT, Gardin JM, Skelton TN, Gottdiener JS, Scott CG, Enriquez-Sarano M. Burden of valvular heart diseases: 
A population-based study. Lancet. 2006;368(9540):100511. https://doi.org/10.1016/s0140-6736(06)69208-8 PMid:16980116

2. Baumgartner $\mathrm{H}$, Hung $\mathrm{J}$, Bermejo $\mathrm{J}$, Chambers JB, Evangelista A, Griffin BP, et al. Echocardiographic assessment of valve stenosis: EAE/ASE recommendations for clinical practice. J Am Soc Echocardiogr. 2009;22(1):1-23. https://doi. org/10.1016/j.echo.2008.11.029

\section{PMid:19130998}

3. Nishimura RA, Otto CM, Bonow RO, Carabello BA, Erwin JP, Guyton RA, et al. 2014 AHA/ACC Guideline for the management of patients with valvular heart disease: A report of the American College of Cardiology/American Heart Association task force on practice guidelines. Circulation. 2014;129(23):e521-643. https:// doi.org/10.1161/cir.0000000000000031

PMid:24589853

4. Hachicha Z, Dumesnil JG, Bogaty P, Pibarot P. Paradoxical low-flow, low-gradient severe aortic stenosis despite preserved ejection fraction is associated with higher afterload and reduced survival. Circulation. 2007;115(22):2856-64. https://doi. org/10.1161/circulationaha.106.668681

PMid: 17533183

5. Pibarot P, Dumesnil JG. Assessment of aortic stenosis severity: When the gradient does not fit with the valve area. Heart. 2010;96(18):1431-3. https://doi.org/10.1136/hrt.2010.195149 PMid:20813724

6. Zoghbi WA, Farmer KL, Soto JG, Nelson JG, Quinones MA. Accurate noninvasive quantification of stenotic aortic valve area by Doppler echocardiography. Circulation. 1986;73(3):452-9. https://doi.org/10.1161/01.cir.73.3.452 PMID:3948355

7. Garcia D, Pibarot P, Dumesnil JG, Sakr F, Durand LG. Assessment of aortic valve stenosis severity: A new index based on the energy loss concept. Circulation. 2000;101(7):765-71. https://doi.org/10.1161/01.cir.101.7.765

PMid:10683350

8. Hachicha Z, Dumesnil JG, Pibarot P. Usefulness of the valvuloarterial impedance to predict adverse outcome in asymptomatic aortic stenosis. J Am Coll Cardiol. 2009;54(11):1003-11. https://doi.org/10.1016/j.jacc.2009.04.079 PMid:19729117

9. Altiok E, Koos R, Schröder J, Brehmer K, Hamada S, Becker M, et al. Comparison of two-dimensional and three-dimensional imaging techniques for measurement of aortic annulus diameters before transcatheter aortic valve implantation. Heart. 2011;97(19):1578-84. https://doi.org/10.1136/hrt.2011.223974 PMid:21700756

10. Messika-Zeitoun D, Serfaty JM, Brochet E, Ducrocq G, Lepage L, Detaint D, et al. Multimodal assessment of the aortic annulus diameter: Implications for transcatheter aortic valve implantation. J Am Coll Cardiol. 2010;55(3):186-94. https://doi. org/10.1016/s1878-6480(10)70157-9 PMid:20117398

11. Utsunomiya H, Yamamoto H, Horiguchi J, Kunita E, Okada T, Yamazato $\mathrm{R}$, et al. Underestimation of aortic valve area in calcified aortic valve disease: Effects of left ventricular outflow tract ellipticity. Int J Cardiol. 2012;157(3):347-53. https://doi. org/10.1016/j.ijcard.2010.12.071

PMid:21236506

12. Kempfert J, Van Linden A, Lehmkuhl L, Rastan AJ, Holzhey D, Blumenstein J, et al. Aortic annulus sizing: Echocardiographic versus computed tomography derived measurements in comparison with direct surgical sizing. Eur J Cardiothorac Surg. 2012;42(4):627-33. https://doi.org/10.1093/ejcts/ezs064 PMid:22402450
13. Shiran A, Adawi S, Ganaeem M, Asmer E. Accuracy and reproducibility of left ventricular outflow tract diameter measurement using transthoracic when compared with transesophageal echocardiography in systole and diastole. Eur J Echocardiogr. 2009;10(2):319-24. https://doi.org/10.1093/ ejechocard/jen254

PMid:18835821

14. Pibarot P, Garcia D, Dumesnil JG. Energy loss index in aortic stenosis: From fluid mechanics concept to clinical application. Circulation. 2013;127(10):1101-4. https://doi.org/10.1161/ circulationaha.113.001130 PMid:23479666

15. Ng AC, Delgado V, Van der Kley F, Shanks M, Van de Veire NR, Bertini M, et al. Comparison of aortic root dimensions and geometries before and after transcatheter aortic valve implantation by 2- and 3-dimensional transesophageal echocardiography and multislice computed tomography. Circ Cardiovasc Imaging. 2010;3(1):94-102. https://doi.org/10.1161/ circimaging.109.885152

PMid:19920027

16. Clavel MA, Rodes-Cabau J, Dumont É, Bagur R, Bergeron S, De Larochellière $\mathrm{R}$, et al. Validation and characterization of transcatheter aortic valve effective orifice area measured by Doppler echocardiography. JACC Cardiovasc Imaging. 2011;4(10):1053-62. https://doi.org/10.1016/j.jcmg.2011.06.021 PMid:21999863

17. Pibarot P, Dumesnil JG. Low-flow, low-gradient aortic stenosis with normal and depressed left ventricular ejection fraction. $J$ Am Coll Cardiol. 2012;60(19):1845-53. https://doi.org/10.1016/j. jacc.2012.06.051 PMid:23062546

18. Jander N, Minners J, Holme I, Gerdts E, Boman K, Brudi P, et al Outcome of patients with low-gradient "severe" aortic stenosis and preserved ejection fraction. Circulation. 2011;123(8):88795. https://doi.org/10.1161/circulationaha.110.983510 PMid:21321152

19. Tribouilloy C, Rusinaru D, Maréchaux S, Castel AL, Debry N, Maizel J, et al. Low-gradient, low-flow severe aortic stenosis with preserved left ventricular ejection fraction: Characteristics, outcome, and implications for surgery. J Am Coll Cardiol. 2015;65(1):55-66. https://doi.org/10.1016/j.jacc.2014.09.080 PMid:25572511

20. Kim KS, Maxted W, Nanda NC, Coggins K, Roychoudhry D, Espinal $\mathrm{M}$, et al. Comparison of multiplane and biplane transesophageal echocardiography in the assessment of aortic stenosis. Am J Cardiol. 1997;79(4):436-41. https://doi. org/10.1016/s0002-9149(96)00782-5

PMid:9052346

21. Malyar NM, Schlosser T, Barkhausen J, Gutersohn A, Buck T, Bartel T, et al. Assessment of aortic valve area in aortic stenosis using cardiac magnetic resonance tomography: Comparison with echocardiography. Cardiology. 2008;109(2):126-34. https:// doi.org/10.1159/000105554

PMid: 17713328

22. Reant $P$, Lederlin $M$, Lafitte $S$, Serri $K$, Montaudon $M$, Corneloup $\mathrm{O}$, et al. Absolute assessment of aortic valve stenosis by planimetry using cardiovascular magnetic resonance imaging: Comparison with transesophageal echocardiography, transthoracic echocardiography, and cardiac catheterisation. Eur J Radiol. 2006;59(2):276-83. https://doi.org/10.1016/j. ejrad.2006.02.011 PMid:16873006

23. Khaw AV, Von Bardeleben RS, Strasser C, Mohr-Kahaly S, Blankenberg S, Espinola-Klein C, et al. Direct measurement of left ventricular outflow tract by transthoracic real-time 3D-echocardiography increases accuracy in assessment of 
aortic valve stenosis. Int J Cardiol. 2009;136(1):64-71. https:// doi.org/10.1016/j.ijcard.2008.04.070

\section{PMid:18657334}

24. Camm J, Lüscher TF, Maurer G, Serruys PW. The ESC Textbook of Cardiovascular Medicine. $2^{\text {nd }}$ ed. England: Oxford University Press;2009. https://doi.org/10.4414/cvm.2018.00567

25. Baumgartner $\mathrm{H}$, Hung J, Bermejo J, Chambers JB, Evangelista A, Griffin BP, et al. Echocardiographic assessment of valve stenosis: EAE/ASE recommendations for clinical practice. Eur J Echocardiogr. 2009;10(1):1-25. https://doi. org/10.1093/ejechocard/jen303

PMid:19065003

26. Chair HB, Co-Chair JH, Bermejo J, Chambers JB, Edvardsen T, Goldstein S, et al. Recommendations on the echocardiographic assessment of aortic valve stenosis: A focused update from the European association of cardiovascular imaging and the American society of echocardiography. Eur Heart J Cardiovasc Imaging. 2017;18(3):254-75. https://doi.org/10.1093/ehjci/ jew335

PMid:28363204 